\title{
Global issues related to enteric viral infections
}

\author{
Ulrich Desselberger
}

Received: 13 May 2014/ Accepted: 22 May 2014/Published online: 27 June 2014

(C) Indian Virological Society 2014

\begin{abstract}
Acute viral gastroenteritis is a major health issue worldwide and is associated with high annual mortality, particularly in children of developing countries. Rotaviruses, caliciviruses and astroviruses are the main causes. Accurate diagnoses are possible by recently developed molecular techniques. In many setups, zoonotic transmission is an important epidemiological factor. Treatment consists of rehydration and is otherwise symptomatic. The worldwide introduction of universal rotavirus vaccination of infants has significantly reduced rotavirus disease and mortality.
\end{abstract}

Keywords Diarrhea - Gastroenteritis · Virus classification - Diagnosis · Vaccine - Pathogenesis . Epidemiology

\section{Introduction}

Acute gastroenteritis (AGE) with diarrhea, vomiting and dehydration in children of $<5$ years of age is a frequent disease with annually 1.4 billion episodes worldwide [11]. Associated annual mortality of 1.3 million children ranges in third position of causes after deaths during the neonatal period and deaths from pneumonia [9]. Of these deaths, 450,000 (approximately one-third) are due to rotavirus (RV)-associated disease, almost two-thirds of them in three sub-Saharan African and three south Asian countries [14]. Besides RVs, other frequent viral causes of AGE in childhood are caliciviruses (of the Norovirus and Sapovirus genera), astroviruses, and enteric adenoviruses (of group F),

U. Desselberger $(\bowtie)$

Department of Medicine, University of Cambridge, Addenbrooke's Hospital, Cambridge CB2 0QQ, UK

e-mail: ud207@medschl.cam.ac.uk with enteroviruses, picobirnaviruses, toroviruses and coronaviruses being detected more rarely [4].

\section{Virus classification}

Rotaviruses are genomically and antigenically highly diverse: they are subdivided into species (A-H), and within species A, the major cause of human infections, various genotypes relating to the surface proteins VP7 (G types, from glycoprotein) and VP4 (P types, from protease-sensitive protein) are differentiated [5]. A more complete genotyping system comprising all 11 genome segments of RVs has recently been developed [4,5], which permits the study of transmission pathways and viral evolution. Similarly, there is much diversity of human caliciviruses (occurring in several genogroups, each containing 1-19 genotypes) and astroviruses (8 genotypes) [4].

\section{Pathogenesis of AGE}

The pathogenesis of RVs is best studied. Diarrhea arises from destruction of the epithelia of the small intestine leading to reduced absorption but also from hypersecretion; the RV nonstructural protein 4 (NSP4) functions as a viral enterotoxin (for details see [5]). The onset of viral AGE is after a short incubation period ( 1 and 2 days) with watery diarrhea (4-7 days), vomiting and varying degrees of dehydration as the main symptoms. The degree of severity of disease varies widely, and inapparent infections, particularly re-infections, are not uncommon.

\section{Diagnosis of viral AGE}

The diagnosis of RV and astrovirus infections is relatively easy since large amounts of virus particles are produced; 
human caliciviruses are synthesized in lower concentrations and for shorter periods. The reverse transcription polymerase chain reaction (RT-PCR) has become the gold standard of diagnosis, due to its high degree of sensitivity and specificity $[4,5]$.

\section{Treatment of AGE}

Treatment consists mainly of oral rehydration or, in severe cases, intravenous rehydration, with standard formulae of oral rehydration fluids recommended by WHO. Otherwise, treatment is mainly symptomatic, since no antivirals specifically directed against RVs, caliciviruses or astroviruses have been licensed yet $[4,5]$.

\section{Immune responses and correlates of protection}

Immune responses to RV infection consist of type-specific and cross-reactive humoral antibody production, $\mathrm{T}$ cell activation and activation of different mechanisms of innate immune responses [5]. Rotavirus-specific secretory $\operatorname{IgA}$ copro-antibodies have been identified as an important factor of protection, but the full correlates of protection remain to be determined $[4,5]$.

\section{Epidemiology}

The epidemiology of RVs, caliciviruses and astroviruses is characterized by co-circulation of different genotypes, with rapid and unpredictable changes of peak prevalences of particular genotypes [4]. The viral transmission is mainly by the faecal-oral route. There is good evidence that RVs which are endemic in various mammalian species can be transmitted to humans [5] by close contact or common sources, e.g. water, and for other enteropathogenic viruses the evidence for zoonotic transmission is increasing.

\section{Vaccine development}

In 2006, two live attenuated RV vaccine candidates have been found to be highly efficacious to prevent severe RV disease [13, 15]. Since then, the vaccines have been licensed in many countries worldwide and are in several locations applied as universal vaccines as a component of Expanded Program of Immunization schedules. Overall, RV vaccination has been found to be highly effective in decreasing RV disease and associated hospitalisation or visits to medical practitioners in developed countries $[3,12]$.
Post-marketing surveillance of co-circulating RV strains has been intensified [7]. The surveillance programmes include animal species (domestic and feral) that are in close contact with humans. The increased attention to animal AGE is on top of already considerable research in this area since animal AGE, apart from affecting animal well-being, has severe negative economic effects on breeding and production programs. Work on developing a vaccine against calicivirus disease is ongoing.

\section{Relevant work presented in this special issue of virus disease}

This special issue of VirusDisease contains contributions on enteric viral infections in humans and animals from both, developed countries and countries under development. Relating to RV epidemiology, data are provided by Papp and associates, Ghosh and Kobayashi, and Maneekarn. Similarly, the incidence of infections with astroviruses has been studied in humans and animals in parallel by Krishnan, infections of kobuvirus by Khamrin and of picobirnaviruses by Ganesh and associates. Although the prevalence of noroviruses as cause of human AGE is high [1], there is still a gap of data from countries under development, especially in Africa. Viruses of avian species (e.g. from turkey) are being studied by Jindal and associates. Although the RT-PCR specific for enteropathogenic RNA viruses has become the diagnostic method of choice, virus isolation in cell culture remains an important tool for strain collections and molecular-biological research projects, and Barman and associated have explored different detection systems for the isolation of RVs in cell culture. Rotavirus pathogenesis has several intriguing features: while the apical epithelia of the small intestinal villi are the primary replication site, the presence of $\mathrm{RV}$ antigen, $\mathrm{RV}$ dsRNA and sometimes infectious RV in blood point at a systemic component of the infection [2]. The clinical significance of extra-intestinal spread of RV is under intense scrutiny and controversial at present, as reviewed by Alfajaro and Cho. Recently, the detection of the presence of viral genomes by molecular techniques in the absence of virus isolation (metagenomics) has opened a new field of microbial research, exploring the significance of the gut 'virome' for health and various enteric diseases and possibly discovering zoonotically transmitted viruses [10]. Banyai has reviewed this novel research approach.

\section{Outlook}

Regrettably, human noroviruses (NoV) and sapoviruses $(\mathrm{SaV})$, genera of the Caliciviridae family, cannot be 
propagated in cell culture at present, and this gap has hampered research. Nonetheless, RT-PCR technology has proven the immense significance of noroviruses as enteric pathogens worldwide $[1,6]$. In countries with established universal RV vaccination NoVs have taken the first position as cause of hospitalisation for AGE in childhood $[8,12]$. It is expected that NoV infections in children will now be studied more intensely worldwide.

This special issue of VirusDisease succeeds in conveying the importance of studying viral enteric pathogens in human and animal in parallel with virtually equal emphasis. There are still considerable gaps in our knowledge, which have a good chance of being filled in the near future.

\section{References}

1. Ahmed SM, Hall AJ, Robinson AE, Verhoef L, Premkumar P, Parashar UD, Koopmans M, Lopman BA. The global prevalence of norovirus among cases of gastroenteritis: a systematic review and meta-analysis. Lancet Infect Dis. 2014; in press.

2. Blutt SE, Kirkwood CD, Parreño V, Warfield KL, Ciarlet M, Estes MK, Bok K, Bishop RF, Conner ME. Rotavirus antigenaemia and viraemia: a common event? Lancet. 2003;362:1445-9.

3. Buttery JP, Lambert SB, Grimwood K, Nissen MD, Field EJ, Macartney KK, Akikusa JD, Kelly JJ, Kirkwood CD. Reduction in rotavirus-associated acute gastroenteritis following introduction of rotavirus vaccine into Australia's National Childhood vaccine schedule. Pediatr Infect Dis J. 2011;30(1 Suppl):S25-9.

4. Desselberger U, Gray J. Viral gastroenteritis. Medicine. 2013;41(12):700-4.

5. Estes MK, Greenberg HB. Rotaviruses. In: Knipe DM, Howley PM, et al., editors. Fields virology. 6th ed. Philadelphia: Wolters Kluwer Health/Lippincott Williams \& Wilkins; 2013. p. $1347-401$.

6. Hoa Tran TN, Trainor E, Nakagomi T, Cunliffe NA, Nakagomi O. Molecular epidemiology of noroviruses associated with acute sporadic gastroenteritis in children: global distribution of genogroups, genotypes and GII.4 variants. J ClinVirol. 2013;56(3): 185-93.

7. Iturriza-Gómara M, Dallman T, Bányai K, Böttiger B, Buesa J, Diedrich S, Fiore L, et al. Rotavirus genotypes co-circulating in Europe between 2006 and 2009 as determined by EuroRotaNet, a pan-European collaborative strain surveillance network. Epidemiol Infect. 2011;139(6):895-909.

8. Koo HL, Neill FH, Estes MK, Munoz FM, Cameron A, Dupont HL, Atmar RL. Noroviruses: the most common pediatric viral enteric pathogen at a large university hospital after introduction of rotavirus vaccination. J Pediatr Infect Dis Soc. 2013;2(1): $57-60$.

9. Liu L, Johnson HL, Cousens S, Perin J, Scott S, Lawn JE, Rudan I, et al. Global, regional, and national causes of child mortality: an updated systematic analysis for 2010 with time trends since 2000. Lancet. 2012;379(9832):2151-6. Erratum in: Lancet. 2012 Oct $13 ; 380(9850): 1308$.

10. Minot S, Bryson A, Chehoud C, Wu GD, Lewis JD, Bushman FD. Rapid evolution of the humangutvirome. Proc Natl Acad Sci USA. 2013;110(30):12450-5.

11. Parashar UD, Hummelman EG, Bresee JS, Miller MA, Glass RI. Global illness and deaths caused by rotavirus disease in children. Emerg Infect Dis. 2003;9(5):565-72.

12. Payne DC, Boom JA, Staat MA, Edwards KM, Szilagyi PG, Klein EJ, Selvarangan R, et al. Effectiveness of pentavalent and monovalent rotavirus vaccines in concurrent use among US children <5 years of age, 2009-2011. Clin Infect Dis. 2013;57(1):13-20.

13. Ruiz-Palacios GM, Pérez-Schael I, Velázquez FR, Abate H, Breuer T, Clemens SC, Cheuvart B, et al. Safety and efficacy of an attenuated vaccine against severe rotavirus gastroenteritis. N Engl J Med. 2006;354:11-22.

14. Tate JE, Burton AH, Boschi-Pinto C, Steele AD, Duque J, Parashar UD, WHO-coordinated Global Rotavirus Surveillance Network. 2008 estimate of worldwide rotavirus-associated mortality in children younger than 5 years before the introduction of universal rotavirus vaccination programmes: a systematic review and meta-analysis. Lancet Infect Dis. 2012;12(2):136-41.

15. Vesikari T, Matson DO, Dennehy P, Van Damme P, Santosham M, Rodriguez Z, Dallas MJ, et al. Safety and efficacy of a pentavalent human-bovine (WC3) reassortant rotavirus vaccine. N Engl J Med. 2006;354:23-33. 